\title{
Strengthening the Health System in India through Ayushman Bharat (AB) - Prime Minister's Jan Arogya Yojana (PM-JAY) - Core Areas to look in to for achieving Sustainable Development Goals (SDG)
}

\section{Nagalapura Prakash}

Associate Dean, Manipal Global Academy of BFSI, No. 36, R.K. Hegde Nagar, Chokkanahalli, Jakkur Post, Bangalore 560064

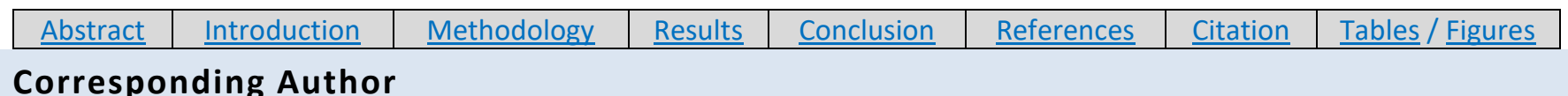

N.S.Prakash, Associate Dean, Manipal Global Academy of BFSI, No. 36, R.K. Hegde Nagar, Chokkanahalli Jakkur Post, Bangalore: 560064

E Mail ID: prakash.ns@manipal.edu

\section{Citation}

Prakash N. Strengthening the Health System in India through Ayushman Bharat (AB) - Prime Minister's Jan Arogya Yojana (PM-JAY) - Core Areas to look in to for achieving Sustainable Development Goals (SDG). Indian J Comm Health. 2020;32(4):737-739. https://doi.org/10.47203/IJCH.2020.v32i04.022

Source of Funding: Nil Conflict of Interest: None declared

Article Cycle

Received: 14/10/2020; Revision: 05/11/2020; Accepted: 28/11/2020; Published: 31/12/2020

This work is licensed under a Creative Commons Attribution 4.0 International License.

\section{Abstract}

Background: Government of India flagged off a very big health scheme for poor in the name of 'Ayushman Bharat' $(A B)$ with a huge increase in medical cover for poorer section of the society from Sep 2018. This covers secondary and tertiary hospitalization care to approximately $40 \%$ of the population. Objectives: As the scheme involves huge financial outlay, this paper attempts to evaluate performance and understand whether the core objectives are met on the lines of Universal Health. Methods: A exhaustive survey of related literatures and published data on the official web site of $A B$ is made. Results: The scheme is reasonably successful in providing financial relief but need to look at areas concerning quality delivery. Conclusions: With the larger objective of 'Universal Health', the beneficiaries list need to be reviewed. The scheme should look at bringing down the out of pocket expenses.

\section{Keywords}

Ayushman Bharat; PM JAY; Out of Pocket Expenses; Secondary Health Care; Tertiary Health Care

\section{Introduction}

Ayushman Bharat is a comprehensive need based health care scheme in India that provides for hospitalization cover in respect of secondary and tertiary care up to INR 500,000 for the family introduced during September 2018 as an initiative through National Health Policy (NHP) 2017. This is an attempt to achieve Sustainable Development Goals on the principle of Universal Health Care and reach All. The scheme covers all members of the identified family without any limit in terms of number of family members and including complications arising out of pre-existing diseases.
With targeted numbers of families at 107.4 Million and 500 Million beneficiaries, it is perceived to be one of the largest programmes. It also marks huge increase in amount of cover offered as compared to most of the previous schemes and also other schemes run by different State Governments. The beneficiaries are those identified in SECC (Socio Economic Caste Census) of 2011 and erstwhile RSBY (Rashtriya Swasthya Bima Yojana) members. The scheme also focusses on establishment of 150,000 Health and Wellness Centres (HWC) by bringing in vast improvement in range of services offered by Primary Health Care Centres with emphasis on maternal and child care areas. The number of 
admissions in hospitals went past 15.58 millions as on 25th Jan 21 and hospitals empanelled crossed 24,200 in number.(1) However, the numbers always gives rosy picture and requires objective analysis. The three major ingredients for success of the scheme are infrastructure, man power and materials. The vast majority of health care i.e. 185,000 facilities hardly meets total of $8 \%$ to $10 \%$ of the required services. This needs to be reversed on priority. Less than $20 \%$ of Health Centres meet with Public Health standards as at March 2017. Therefore, necessary focus needs to be made on improving the quality parameters also. Decision is taken in $A B$ to upgrade the services of 150,000 Health Centres and make services available within 30 minutes by foot. Areas for improvement seems quite well identified in $A B$ but needs translation in to end results through proper implementation. Improved HWCs both across rural and urban areas, Strengthening the Primary Health Care Centres (PHCs), Improving the efficiency of PHCs, Enlarging the services to include NonCommunicable Diseases (NCDs) etc are priority. (2)

As per World Health Organization's (WHO) global monitoring report of 2017, $17.3 \%$ of Indians spend more than $10 \%$ of their annual income for treatment and $3.9 \%$ spend more than $25 \%$. Government's capability is limited to $20 \%$ of population as per National Health Policy and $80 \%$ people depend on private facilities. The number of Doctors available is limited to 7 per 10,000 population against required 10 number. Of this 7, only 4 Doctors are effectively engaged in Healthcare Service. Political Will is key to address these problems apart from improving the resources, good long term planning followed by proper implementation. Jan Aushadhi has a limited impact on reducing the Out of Pocket (OOP) expenses. (3)

Public Health Expenditure in India is just over 1\% of GDP which is lowest in the world thus resulting in host of problems mainly with regard to shortfall in meeting quality health care. Issues related to Governance, Stewardship and Quality Control calls for closer attention. While $A B$ scheme is vehicle to take the country to SDG, the resource constraints affect the speed in implementation. Vested interest and possible derailing by private healthcare providers needs to be closely monitored not withstanding the fact that private players will hold key to success. (4)

As huge focus is being given to revamp the HWC as a part of Primary and Preventive Health Care, the middle level health care provider and nurses will play vital role of the entire scheme. The disease based programmes initiated earlier such as National Dialysis Programme, National Mental Health Programme, etc have not proved to be good decision at the cost of comprehensive primary health care which should have been the priority. Discontinuation of vertical health programme shall give way for comprehensive health programme which will help in avoiding unnecessary wastage of money in number of duplicate programmes. (5)

There is dearth of human resource to properly set up and operate 150,000 HWCs as planned. Lack of regulatory initiative may cause hurdle for quality delivery. Inadequate budgetary allocation can affect the smooth flow of the work. However, the commendable point in $A B$ being the huge focus and exhaustive manner in which each and every minute area is being addressed that will support the success of the scheme. The experience gained in RSBY scheme has come in very handy for the Government. $62.6 \%$ of the total expenses on health by an household is towards OOP expenses which needs to be looked into as the same is not covered in AB. (6) One of the fundamental problem dogging all public health care in India is Lack of Accountability. Over a period of time, number of unfortunate incidents (like fire, accidental stoppage of oxygen supply to patient etc) have occurred leading to loss of lives whilst in Hospital which have not been put in to root cause analysis to prevent recurrence. Accountability shall be directly linked to level of care and safety of patients. PHCs have been perennially understaffed with last study putting the vacancies at $18 \%$ for Doctors, $15 \%$ for nurses, $30 \%$ for paramedics.(7)

\section{Summary}

$A B$ scheme gives reasonable financial relief to poor families. The efforts of the Government to rope in good number of private hospitals, utilization of hospitals of Railways, ESIC, Public Sector Undertakings etc, also is a welcome step. The size of targeted population being at 500 million, covering $40 \%$ of the population, embraces Universal Health. The focus on improving the HWCs with better facilities demonstrates commitment. The innovative methods for fraud control, portability, close monitoring the performance of hospitals and personnel, IT platform, paperless and user friendly approach, corporate culture within the Administration team, etc also takes this initiative 
closer to reality. The list of beneficiaries however needs to be relooked as it is noted in various surveys that, many deserving people are left out of the scheme unfortunately. Also, the closer attention to points mentioned in preceding paras arising out of the research survey, will certainly make this Programme as one of the most enviable and highly successful programme, globally.

\section{References}

1. https://pmjay.gov.in/about/pmjay (Accessed on $25 \mathrm{Dec}$ 2020)

2. Lahariya C. 'Ayushman Bharat' Program and Universal Health Coverage in India. Indian Pediatr. 2018 Jun 15;55(6):495-506. PMID: 29978817.[PubMed]

3. Chopra H, "Universal Health Coverage- a reality or mirage", Indian Journal of Community Health, 2018;30(2):103-106
4. Angell BJ, Prinja S, Gupt A, Jha V, Jan S. The Ayushman Bharat Pradhan Mantri Jan Arogya Yojana and the path to universal health coverage in India: Overcoming the challenges of stewardship and governance. PLoS Med. 2019;7;16(3):e1002759.

doi:

10.1371/journal.pmed.1002759. PMID: 30845199; PMCID: PMC6405049.[PubMed].

5. Kumar R. Universal health coverage - Time to dismantle vertical public health programs in India. J Family Med Prim Care. 2019;8(4):1295-1296. doi: 10.4103/jfmpc.jfmpc_310_19. PMID: 31143709; PMCID: PMC6510079.[PubMed]

6. Chellaiyan VG, Rajasekar H, Taneja N, "Pradhan Mantri Jan Arogya Yojana - Ayushman Bharat". Indian Journal of Community Health, 2020,32(2): $337-340$

7. Priyadarshi $M$, Kumar S. Accountability in Healthcare in India. Indian J Community Med. 2020;45(2):125-129. doi: 10.4103/ijcm.IJCM_224_19. Epub 2020 Jun 2. PMID: 32905344; PMCID: PMC7467206.[PubMed] 